\begin{tabular}{|c|l|}
\hline Title & Oxidation of $\beta$-SiA IONs prepared by a combination of combustion synthesis and spark plasma sintering \\
\hline Author(s) & Yi, X uemei; Y amauchi, A kira; Kurokawa, Kazuy a; A kiyama, Tomohiro \\
\hline Citation & $\begin{array}{l}\text { Corrosion Science, 52(5), 1738-1745 } \\
\text { https://doi.org/10.1016j.corsci.2010.02.006 }\end{array}$ \\
\hline Issue Date & 2010-05 \\
\hline Doc URL & http://hdl.handle.net/2115/43067 \\
\hline Type & article (author version) \\
\hline File Information & CS52-5_1738_1745.pdf \\
\hline
\end{tabular}

Instructions for use 


\title{
Oxidation of $\beta$-SiAlONs prepared by a combination of combustion synthesis (CS) and spark plasma sintering (SPS)
}

\author{
Xuemei Yi, Akira Yamauchi, Kazuya Kurokawa, Tomohiro Akiyama * \\ Center for Advanced Research of Energy Conversion Materials, Hokkaido University,
} Kita 13 Nishi 8, Kita-ku, Sapporo 060-8628, Japan

\begin{abstract}
The oxidation behavior of $\beta-\mathrm{Si}_{6-z} \mathrm{Al}_{z} \mathrm{O}_{z} \mathrm{~N}_{8-\mathrm{z}} \mathrm{S}(\mathrm{z}=1,2$, and 3 ) prepared by a combination of combustion synthesis (CS) and spark plasma sintering (SPS) was investigated. The oxidation experiments were conducted at temperatures of $1000{ }^{\circ} \mathrm{C}$, $1200{ }^{\circ} \mathrm{C}$, and $1400{ }^{\circ} \mathrm{C}$ in air for $100 \mathrm{~h}$ (360 ks). Their oxidation kinetics follows a parabolic rate law, and the deviation from that increases with a decrease in the $z$ value. The results of XRD and EPMA showed that the oxide formed on $\beta$-SiAlONs $(z=1$ and 2) consists of silica and mullite, and on $\beta$-SiAlON $(z=3)$ of only mullite.

Keywords: A. Ceramic; B. X-ray diffraction; B. SEM; C. Oxidation
\end{abstract}

*Corresponding author: Tel.: +81 11706 6849; fax: +81 117260731.

E-mail address: takiyama@eng.hokudai.ac.jp (T. Akiyama) 


\section{Introduction}

$\beta$-SiAlONs are the solid solution of $\beta-\mathrm{Si}_{3} \mathrm{~N}_{4}$ in which $\mathrm{Si}-\mathrm{N}$ has been substituted with an equivalent amount of $\mathrm{Al}-\mathrm{O}$. They are commonly described by the general formula $\beta-\mathrm{Si}_{6-z} \mathrm{Al}_{z} \mathrm{O}_{z} \mathrm{~N}_{8-z}$, where $z$ takes values from 0 to 4.2 [1,2]. $\beta$-SiAlONs have been attracting considerable attention on account of their excellent mechanical and thermal properties, superior chemical stability, and conspicuous thermal-shock resistance. Consequently, they are suitable for high-temperature applications, and they are being extensively used as high-temperature engineering ceramics in cutting tools and abrasive materials [3].

Combustion synthesis (CS), known as self-propagating high-temperature synthesis, has been attracting growing interest on account of its capacity for energy saving, short reaction time, and its ability of forming high purity products [4]. In our previous papers [5-7], $\beta$-SiAlON powders were successfully synthesized under only $1 \mathrm{MPa}$ of nitrogen pressure assisted with mechanical activation. Sintering methods such as pressureless sintering [8], hot isostatic pressing [2], and spark plasma sintering (SPS) [9] have been previously used to produce dense $\beta$-SiAlONs. Among these aforementioned methods, SPS technique is similar to conventional hot press (HP), but it allows a pulsed direct current instead of external heating source to heat the sample through the die, so the die also acts as a heating source. Therefore, it is regarded as a rapid and effective densification technique for ceramics as well as other hard materials. 
As is known, under high temperature conditions, the oxidation resistance becomes important for the practical uses of $\beta$-SiAlONs. The oxidation behavior of hot isostatically pressed $\beta$-SiAlONs $(z=0.5,3.8)$ with and without yttria additive has been studied in flowing oxygen atmosphere [10], and their oxidation kinetics has been shown to be influenced by sintering aid yttria, which was added to enhance the densification process. The oxidation kinetics of reaction sintered $\beta$-SiAlON $(z=3)$ powder was studied under both isothermal and non-isothermal condition [11], and a new kinetics model was applied to calculate the oxidation behavior of SiAlON. Early-stage oxidation of carbothermally synthesized $\beta$-SiAlON $(z=2.45)$ powder was studied $[12,13]$, which indicated that amorphous silica was formed at early stage, and followed by the formation of an amorphous aluminosilicate. The synthesis method is the carbothermal reduction and nitridation of the clay mineral kaolinite in which the clay was mixed with carbon and heated at high temperature in flowing purified nitrogen ${ }^{*}$. Hot-pressed $\beta$-SiAlON ( $z=3$ ) without additive was investigated in different atmospheres by Kiyono and Shimada [14]. However, to our best knowledge, there are very few reports on the oxidation behavior of CS-SPSed $\beta$-SiAlONs. Therefore, the purpose of this paper was to investigate the oxidation behavior of dense $\beta$-SiAlONs at different temperatures in air, which were synthesized by a combination of CS and SPS without any sintering aids. The effect of the $z$ value on the oxidation kinetics and products was systemically examined. The results obtained would give valuable information for the design of

\footnotetext{
${ }^{*} 3 \mathrm{Al}_{2} \mathrm{Si}_{2} \mathrm{O}_{5}(\mathrm{OH})_{4}+15 \mathrm{C}+5 \mathrm{~N}_{2} \rightarrow 2 \mathrm{Si}_{3} \mathrm{Al}_{3} \mathrm{O}_{3} \mathrm{~N}_{5}+6 \mathrm{H}_{2} \mathrm{O} \uparrow+15 \mathrm{CO} \uparrow$
} 
$\beta$-SiAlONs for the engineering application at high temperature. 


\section{Experimental procedure}

\subsection{Sample preparation}

The synthesis method has been described in detail elsewhere [15], so here we only repeated the preparation method simply.

Commercially available powders of Si (98\% purity, 1-2 $\mu \mathrm{m}$ in size), $\mathrm{Al}$ (99.9\% purity, $3 \mu \mathrm{m}$ in size), and $\mathrm{SiO}_{2}$ (99.9\% purity, $0.8 \mu \mathrm{m}$ in size) were used as starting materials. $\beta$-SiAlON powders (CSed product, unknown purity, $0.5 \mu \mathrm{m}$ in size) were added as the diluent. The chemical reaction for the synthesis of $\beta$-SiAlON from the abovementioned starting materials can be shown as follows:

$$
(6-1.5 z) S i+z A l+0.5 z \mathrm{SiO}_{2}+(4-0.5 z) N_{2} \rightarrow \beta-\mathrm{Si}_{6-z} A l_{z} O_{z} N_{8-z}
$$

where, $z$ takes values of 1,2 , and 3 . The mass percent of each starting composition was calculated according to equation (1), and is shown in Table 1. The mass percent of the diluent was determined according to our preliminary experiment.

The CSed powder was first subjected to planetary ball milling for $60 \mathrm{~min}$, then was compacted into a carbon die of $10 \mathrm{~mm}$ in inner diameter and sintered using a SPS system under vacuum of lower than $4 \mathrm{~Pa}$ at a compressive stress of $50 \mathrm{MPa}$. The resulting compacts were heated from room temperature to $600{ }^{\circ} \mathrm{C}$ in $5 \mathrm{~min}$, and then 
were heated to $1600{ }^{\circ} \mathrm{C}$ at a rate of $30{ }^{\circ} \mathrm{C} / \mathrm{min}$. The compacts were maintained at this temperature for 10 min before the power was turned off.

\subsection{Isothermal oxidation test}

The flat surfaces and sides of the sintered discs were first ground to remove the carbon foil stuck to them during high temperature sintering, and subsequently, the surfaces were ground and polished to parallel to each other and mirror. After polishing, the diameter and thickness of each disc were carefully measured to calculate its surface area. Prior to oxidation, the polished specimens were ultrasonically cleaned in ethanol, then placed in an alumina boat and then placed into the hot zone of a high temperature tube furnace. Isothermal oxidation was performed at $1000^{\circ} \mathrm{C}, 1200^{\circ} \mathrm{C}$, and $1400^{\circ} \mathrm{C}$ for up to $100 \mathrm{~h}$ in air, and at each temperature the specimens were taken out of the furnace at intervals of $1,24,50$, and $100 \mathrm{~h}$ to check the mass gain using an analytical balance with an accuracy of $\pm 0.001 \mathrm{mg}$.

\subsection{Characterization}

The bulk density of CS-SPSed specimens was measured according to the Archimedean principle, using distilled water as the medium. The phases were analyzed

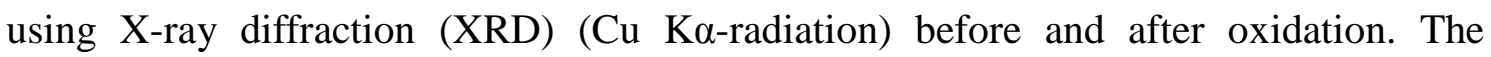


microstructure of the oxidized surfaces was examined using a scanning electron microscope (SEM) equipped with an energy dispersive X-ray spectrometer (EDS). 


\section{Results and discussion}

\subsection{Characterization of CS-SPSed $\beta$-SiAIONs}

The densities of single-phase $\beta$-SiAlONs ( $z=1,2$, and 3) produced by SPS of CSed powders without any sintering aids are shown in Table 2, in which the theoretical densities were taken from reference [16]. The average value of three specimens was taken as the representative bulk density for each group. The bulk density decreases with an increase in the $z$ value. The relative density reached $98.8 \%$ of the corresponding theoretical density when $z=1$, and is larger than $99 \%$ when $z=2$ and 3 .

\subsection{Oxidation kinetics}

The mass gains per unit surface area are shown in Fig. 1 as a function of oxidation time at different temperatures. The final mass gain increases clearly with an increase in temperature and also with the $z$ value. The mass gains are small for the oxidation at $1000{ }^{\circ} \mathrm{C}$ and $1200{ }^{\circ} \mathrm{C}$. However, they are very large at $1400{ }^{\circ} \mathrm{C}$ for all of the samples. At the initial stage of oxidation at $1400{ }^{\circ} \mathrm{C}$, the mass gain is slower for $\mathrm{Z} 3$ than for $\mathrm{Z} 1$ and Z2. The final mass gains were $4.21,4.77$, and $6.05 \mathrm{~g} \mathrm{~m}^{-2}$ for $\mathrm{Z} 1, \mathrm{Z} 2$, and $\mathrm{Z} 3$, respectively at $1400{ }^{\circ} \mathrm{C}$ for $100 \mathrm{~h}$. The mass gain is similar to that of HIPed $\beta$-SiAlON [10], but in view of energy and time saving, our CS-SPS method shows valuable and 
economical for the practical use.

The oxidation kinetics of $\mathrm{Si}_{3} \mathrm{~N}_{4}$ and $\mathrm{SiAlON}$ have been previously reported to obey a parabolic rate law $[12,17]$. However, some of our oxidation curves deviated from the parabolic rate law, and they varied with the $z$ value. The mass gain can be expressed by the following rate raw:

$$
\frac{\Delta m}{A}=k t^{n}+c
$$

where, $\Delta m(\mathrm{~g})$ is oxidation mass gain, $A\left(\mathrm{~m}^{2}\right)$ is original specimen surface area, $k\left(\mathrm{~g} \mathrm{~m}^{-2}\right.$ $\mathrm{s}^{-\mathrm{n}}$ ) is oxidation rate constant, $t(\mathrm{~s})$ is time, $n(-)$ is exponent, and $c(-)$ is a numerical constant.

The exponent $n$ in equation (2) can be obtained from the slopes of the lines shown in Fig. 2, which shows the log-log plots of the mass gain per unit surface area to oxidation time. The slopes vary between $1 / 3$ and $1 / 2$ for all the specimens at different oxidation temperatures, and increase with an increase in the $z$ value. The slopes of $\mathrm{Z3}$ are close to $1 / 2$ at all the temperatures, and this indicates that the oxidation of $\mathrm{Z3}$ follows a parabolic rate law and is diffusion-controlled. However, for samples Z1 and $Z 2$, the slopes at all the temperatures are lower than $1 / 2$. This indicated that the oxidation of $\beta$-SiAlONs with lower $z$ values deviated a little from a parabolic rate law and was slower than those with higher $z$ values with increasing oxidation time. The deviation from a parabolic raw can be attributed to the change of conformation or 
component in the scale with oxidation time commonly. The reason for the deviation of our samples will be explained later.

Fig. 3 shows the mass gain as a function of oxidation time of CS-SPSed $\beta$-SiAlONs comparing with $\mathrm{Si}_{3} \mathrm{~N}_{4}$ [18] at $1200{ }^{\circ} \mathrm{C}$. Reference [18] presented the oxidation (and also corrosion) of hot pressed $\mathrm{Si}_{3} \mathrm{~N}_{4}$ with different sintering aids, such as $\mathrm{Al}_{2} \mathrm{O}_{3}, \mathrm{Y}_{2} \mathrm{O}_{3}$, and $\mathrm{MgO}_{2}$, and of commercial $\mathrm{Si}_{3} \mathrm{~N}_{4}$ with $\mathrm{Lu}_{2} \mathrm{O}_{3}$ as sintering aid. Its conclusions showed that the oxidation (and also corrosion) resistance was clearly affected by sintering aids, and SN-A $\left(\mathrm{Si}_{3} \mathrm{~N}_{4}\right.$ with $\mathrm{Al}_{2} \mathrm{O}_{3}$ as sintering aid) and SN282 $\left(\mathrm{Si}_{3} \mathrm{~N}_{4}\right.$ with $\mathrm{Lu}_{2} \mathrm{O}_{3}$ as sintering aid) had the best oxidation resistance. It is clear in Fig. 3 that the mass gain of SN-A is much larger than that of our CS-SPSed $\beta$-SiAION, which could be attributed to the low relative density (94\%) of SN-A. On the other hand, the mass gain of SN282 is similar to those of the CS-SPSed $\beta$-SiAlONs with the lower $z$ values. In view of the cost and properties of $\mathrm{Lu}_{2} \mathrm{O}_{3}$ sintering aid used in SN282, the CS-SPSed $\beta$-SiAlONs without sintering aids showed good oxidation resistance and are economical for the practical use.

\subsection{Oxidation products and microstructure of oxide scale}

Fig. 4 shows photos of the specimens after $100 \mathrm{~h}$ oxidation in air. For all of the specimens the colour changes gradually from grey toward white with increasing temperature, but only after $1400{ }^{\circ} \mathrm{C}$ oxidation the colour of $\mathrm{Z3}$ is clearly white. The 
other specimens show a little colour change. This could be attributed to the fact that most of the oxides were amorphous (this will be shown later), except for Z3 oxidized at $1400{ }^{\circ} \mathrm{C}$, whose surface oxides crystallized entirely.

XRD patterns before and after the oxidation for $100 \mathrm{~h}$ are shown in Fig. 5, and all of the peaks have been compared with JCPDS cards. There were no impurity peaks detected except for $\beta$-SiAlON peaks after SPS, which indicated that pure $\beta$-SiAlONs were produced. For Z1, see Fig. 5a, there are no visible changes for oxidation at $1000{ }^{\circ} \mathrm{C}$ compared with the as-sintered product. However, after $1200{ }^{\circ} \mathrm{C}$ oxidation, a silica (cristobalite) peak was detected and a very few mullite peaks were also detected. When the temperature reached to $1400{ }^{\circ} \mathrm{C}$, the intensity of mullite peaks became stronger and more peaks were visible, and the peak of cristobalite was still visible. For Z2, see Fig. 5b, it showed similar change with Z1, but according to the intensity of the XRD peaks, the quantity of cristobalite was fewer for $\mathrm{Z} 2$ than $\mathrm{Z} 1$ at $1200{ }^{\circ} \mathrm{C}$. On the other hand, for Z3 shown in Fig. 5c, no cristobalite peak was detected at any temperature and only mullite peaks were visible for $1200{ }^{\circ} \mathrm{C}$ and $1400{ }^{\circ} \mathrm{C}$ oxidation.

It is a general agreement that the reaction product is amorphous at initial-stage of oxidation and at a low temperature, but the product tends to crystallize after a longer time and at higher temperatures. In our experiments, no visible oxide peaks were detected by XRD when the temperature was $1000{ }^{\circ} \mathrm{C}$. This is attributable to the formation of amorphous oxides. This can also explain why the aforementioned colour of the specimens after oxidation changed from grey toward white with increasing 
temperature. From the XRD results, we can conclude that amorphous silica was formed at initial stage of oxidation for $\beta$-SiAlONs with lower $z$ values, but with an increase in the $z$ value or the temperature, also with the oxidation time, amorphous silica tended to crystallize, and crystalline mullite increased as the oxidation product. In our aforementioned results shown in Fig. 1, at initial stage of oxidation, the mass gain shows higher at lower $z$ values than that at higher $z$ values. This can be explained by the reason that oxygen diffuses more easily in an amorphous phase than in a crystalline. Using the above analyses, we can also explain why the aforementioned oxidation kinetics results showed a little deviation from a parabolic rate law of $\beta$-SiAlONs with lower $z$ values, which can be attributed to the phase change from amorphous to crystalline and also the component change from silica to mullite in the scale with the oxidation progressing.

SEM micrographs of the surfaces after oxidation at $1000{ }^{\circ} \mathrm{C}, 1200{ }^{\circ} \mathrm{C}$, and $1400{ }^{\circ} \mathrm{C}$ are shown in Figs. 6 to 8, respectively. The microstructures of the oxide scale surfaces varied considerably with oxidation temperature. After $1000{ }^{\circ} \mathrm{C}$ oxidation, no visible oxide crystals could be seen except for some bubbles on the surface of Z1, see Fig. 6a. For Z2 (Fig. 6b), there also no obvious oxide crystals could be seen but its surface looked more porous than the surface of Z1. However, for Z3, see Fig. 6c, the microstructure looked very different from that of Z1 and Z2, and there were visible agglomerates of oxide particles on the surface, and these should be mullite according to the results of XRD. 
After $1200{ }^{\circ} \mathrm{C}$ oxidation (see Fig. 7), there were large numbers of white needle-like oxides of less than $1 \mu \mathrm{m}$ in length on the surface of Z1, see Fig. 7a. The typical EDS analyses of some points in Figs. 7 and 8 are shown in Table 3. Combining the EDS analysis and XRD result, we are convinced that the needle-like oxides should be mullite crystals which grew in amorphous $\mathrm{SiO}_{2}$. No oxide crystals were seen on the surface of Z2, Fig. 7b, except for large numbers of white spots which should be the same mullite as the needle-like crystals in Z1. However, their size was smaller than that in Z1. Fig. 7c shows the microstructure of $\mathrm{Z3}$. We can see that the surface of the specimen was oxidized considerably. Combining the element analysis with the result of XRD, we can conclude that the oxide is mullite.

When the oxidation temperature was increased to $1400{ }^{\circ} \mathrm{C}$ (Fig. 8), the needle-like mullite crystals in Z1, see Fig. 8a, grew up to more than about $10 \mu \mathrm{m}$ in length. In Z2, see Fig. 8b, the mullite showed two kinds of shapes, needle-like crystals and agglomerates. The needle-like crystals were the same as those in Z1, and the agglomerates were as same as those in Z3 shown in Fig. 7c. The whole surface of Z3 (Fig. 8c) is covered with the scale consisting of agglomerates of mullite.

\subsection{Reaction mechanisms}

The aforementioned results indicate that the main solid oxidation products are cristobalite and mullite for $\beta$-SiAlONs. Therefore, the oxidation reaction could be 
expressed by the following equation [10]:

$$
\beta-\mathrm{Si}_{6-z} \mathrm{Al}_{\mathrm{z}} \mathrm{O}_{z} N_{8-z}+\frac{24-3 \mathrm{z}}{4} \mathrm{O}_{2} \rightarrow \frac{18-4 \mathrm{z}}{3} \mathrm{SiO}_{2}+\frac{\mathrm{z}}{6} 3 \mathrm{Al}_{2} \mathrm{O}_{3} \bullet 2 \mathrm{SiO}_{2}+\frac{8-\mathrm{z}}{2} \mathrm{~N}_{2}
$$

here, in our experiments, $z=1,2$, and 3. According to this equation, with an increase in the $z$ value, the quantity of mullite will increase, and contrarily, that of silica and nitrogen gas will decrease.

In the $\beta$-SiAlONs, with increasing $z$ value, more Si-N bonds are replaced with Al-O bonds, and this means that the ratio of $\mathrm{Si}$ to $\mathrm{Al}$ decreases. Therefore, in the $\beta$-SiAlONs with lower $z$ values, at initial-stage of oxidation $\mathrm{Si}$ reacted with $\mathrm{O}$ to form $\mathrm{SiO}_{2}$. As the oxidation proceeds, more $\mathrm{Si}$ is consumed and when the ratio of Si to $\mathrm{Al}$ decreases to a certain level, $\mathrm{Al}$ reacted with $\mathrm{O}$ to form $\mathrm{Al}_{2} \mathrm{O}_{3}$ which reacts with $\mathrm{SiO}_{2}$ to form mullite crystals. On the contrary, in the $\beta$-SiAlONs with higher $z$ values, the ratio of $\mathrm{Si}$ to $\mathrm{Al}$ is low, so mullite is formed in the entire oxidation process and no separate $\mathrm{SiO}_{2}$ could be formed in the oxide scale. This could explain why there was $\mathrm{SiO}_{2}$ detected in $\mathrm{Z} 1$ and $\mathrm{Z} 2$ after oxidation, while only mullite was detected in Z3, cf. the XRD results.

Fig. 9 shows SEM images of the discs after $100 \mathrm{~h}$ oxidation at 1200 and $1400{ }^{\circ} \mathrm{C}$. There are many bubbles on the surfaces of the discs oxidized at $1400{ }^{\circ} \mathrm{C}$. Fig. 9a shows that the bubbles on the surface of Z1 are very big, and many of them cracked. The diameter of cracked holes seems bigger than $50 \mu \mathrm{m}$; however, the surface of $\mathrm{Z} 1$ oxidized at $1200{ }^{\circ} \mathrm{C}$ was flat with no visible bubbles, see Fig. 9d. The bubbles on 
surfaces of Z2 and Z3 after $1400{ }^{\circ} \mathrm{C}$ oxidation are getting smaller with increasing $\mathrm{Z}$ value, see Fig. 9b and c.

Fig. 10 shows SEM images of the cross-sections of the discs Z1, Z2, and Z3 oxidized at $1400{ }^{\circ} \mathrm{C}$ for $100 \mathrm{~h}$. The thickness of the oxide scale seems close to each other for all of the specimens and looks to be about $15 \mu \mathrm{m}$. The oxide scale on $\mathrm{Z} 1$ seems dense, but the scales on Z2 and Z3 have some pores with the latter having more pores than the former. There are a few large pores near the scale surface, and pores near the interface to the substrate are more numerous but smaller.

Combining with the images shown in Fig. 9 and Fig. 10, we can deduce that the bubbles on the surface and the pores in the oxide scale should be attributed to nitrogen gas generated at the interface between the scale and substrate during the oxidation which can be expressed by equation (3). With the progress of oxidation, more nitrogen gas is generated and tends to pass through the oxide scale from the reaction interface to outside of the disc, and then is concentrated in a form of bubbles to some places near the outer surface. Therefore, the pores near the outer surface are big and those near the interface are small. If the oxide scale consisted almost of $\mathrm{SiO}_{2}$, because most of the $\mathrm{SiO}_{2}$ existed as amorphous phase, it would be so soft that all of the nitrogen gas can pass through it to reach the outer surface easily. However, if the oxide scale consisted almost of mullite, because it crystallized entirely, it would be so hard that it does not allow the nitrogen gas to pass through it. Thus, most of the gas remained in the scale. The above consideration can explain why there were no pores in the oxide scale on $\mathrm{Z1}$, but some 
pores were formed for Z2 and Z3, and also with increasing z value, the pores increased. The bubbles on the surfaces can be attributed to the nitrogen gas trapped in the scale before cooling down.

This reaction processes can be explained by the schematic illustration of the oxidation mechanism shown in Fig. 11. From the above analyses, the mechanism of oxidation reaction for the $\beta$-SiAlONs was a diffusion-controlled process and could be described as the following steps which show similar to the oxidation of AIN [19]:

(a) Transfer of oxygen molecules to the surface of $\beta$-SiAlON.

(b) Physisorption of oxygen molecules.

(c) Dissociation of oxygen molecules and chemisorption.

(d) Diffusion of oxygen through the oxide scale to the scale/substrate interface.

(e) Chemical reaction producing oxide and nitrogen gas.

(f) Gas diffusion through the oxide scale to its outer surface.

In conclusion, according to the results, dense protective oxide scale can be formed at high temperature for the $\beta$-SiAlON with lower $z$ values. Therefore, they are suitable for the application as high-temperature engineering ceramics. However, for the $\beta$-SiAlON with higher $z$ values, the strength of oxide scale could be affected by the pores formed in the scale at high temperature. We need more experimental results to verify the durability of these compacts for high temperature application. 


\section{Conclusions}

The oxidation of dense $\beta-\mathrm{Si}_{6-z} \mathrm{Al}_{z} \mathrm{O}_{z} \mathrm{~N}_{8-\mathrm{z}} \mathrm{s}$ with different $z$ values $(z=1,2$, and 3$)$ prepared by a combination of combustion synthesis and spark plasma sintering was investigated at temperatures of $1000{ }^{\circ} \mathrm{C}, 1200{ }^{\circ} \mathrm{C}$, and $1400{ }^{\circ} \mathrm{C}$ in air for $100 \mathrm{~h}$ (360 ks). The following results were obtained:

(i) The oxidation kinetics of the $\beta$-SiAlONs obeys a parabolic rate law well when $z$ $=3$, but for $z=1$ and 2 it deviates a little from that, and the deviation increases with a decrease in the $z$ value.

(ii) The oxide scale consists of silica and mullite for $z=1$ and 2 , and with increasing $z$ value the ratio of mullite increases, but for $z=3$ there is only mullite. Most of the silica is amorphous phase while the mullite is entirely crystalline.

(iii) The oxide scale has more pores with increasing $z$ value. The pore formation is attributed to the nitrogen gas trapped in the scale consisting of crystallized mullite, which is so hard that the nitrogen gas can not pass through. 


\section{Acknowledgements}

We thank Professor S. Taniguchi for giving help on the discussion on our experimental results and also for reviewing the draft. We also thank Prof. T. Watanabe for valuable discussions on our study. 


\section{References}

[1] K.H. Jack, Sialons and related nitrogen ceramics, J. Mater. Sci. 11 (1976) 1135-1158.

[2] T. Ekström, P.O. Käll, M. Nygren, P.O. Olssen, Dense single-phase $\beta$-sialon ceramics by glass-encapsulated hot isostatic pressing, J. Mater. Sci. 24 (1989) 1853-1861.

[3] T. Ekström, M. Nygren, SiAlON Ceramics, J. Am. Ceram. Soc. 75 (1992) 259-276.

[4] Z.A. Munir, U. Anselmi-Tamburini, Self-propagating exothermic reactions: The synthesis of high-temperature materials by combustion, Mater. Sci. Rep. 3 (1989) 277-365.

[5] K. Aoyagi, T. Hiraki, R. Sivakumar, and T. Watanabe, T. Akiyama, Mechanically Activated Combustion Synthesis of beta- $\mathrm{Si}_{6-z} \mathrm{Al}_{z} \mathrm{O}_{z} \mathrm{~N}_{8-z}(z=1-4)$, J. Am. Ceram. Soc. 90 [2] (2007) 626-628.

[6] K. Aoyagi, T. Hiraki, R. Sivakumar, T. Watanabe, T. Akiyama, A new route to synthesize [beta]-Si $\mathrm{S}_{6-\mathrm{z}} \mathrm{Al}_{z} \mathrm{O}_{z} \mathrm{~N}_{8-z}$ powders, J. Alloy. Compd. 441 (2007) 236-240.

[7] R. Sivakumar, K. Aoyagi, and T. Akiyama, Effect of mechanically activated raw materials on beta-sialon formation by combustion synthesis, J. Mater. Res. 22 [10] (2007) 2863-2867.

[8] J. Lis, S. Majorowski, J. A. Puszynski, V. Hlavacek, Dense $\beta$ - and $\alpha / \beta$-SiAlON Materials by Pressureless Sintering of Combustion-Synthesized Powders, Ceramic 
Bulletin. 70[10] (1991) 1658-1664.

[9] Z. Shen, H. Peng, M. Nygren, Rapid densification and deformation of Li-doped sialon ceramics , J. Am. Ceram. Soc. 87[4] (2004) 727-729.

[10] J. Persson, M. Nygren, The Oxidation Kinetics of $\beta$-Sialon Ceramics, J. Eur. Ceram. Soc. 13 (1994) 467-484.

[11] X. M. Hou, K. C. Chou, F. S. Li, Some new perspectives on oxidation kinetics of SiAlON materials, J. Eur. Ceram. Soc. 28[6] (2008) 1243-1249.

[12] S. Shimada, T. Aoki, H. Kiyono, Early-stage thermal oxidation of carbothermal beta-sialon powder, J. Am. Ceram. Soc. 81[1] (1998) 266-268.

[13] K. J. D. MacKenzie, S. Shimada, T. Aoki, Thermal oxidation of carbothermal ß’'-sialon powder: reaction sequence and kinetics, J. Mater. Chem. 7[3] (1997) 527-530. [14] H. Kiyono, S. Shimada, Thermal oxidation of sintered beta-sialon $(z=3)$ ceramics in atmospheres with water vapor, Key Engineering Materials, 264-268 (2004) 893-896. [15] X. Yi, K. Watanabe, and T. Akiyama, Fabrication of dense $\beta$-SiAlON by a combination of combustion synthesis (CS) and spark plasma sintering (SPS), Intermetallics, (2009) Accepted Manuscript.

[16] M. Haviar, A. Johannsen, Unit-cell dimention of $\beta$-sialon, Adv. Ceram. Mater. 3[4] (1988) 405-407.

[17] S. C. Singhal, Thermodynamics and kinetics of oxidation of hot-pressed silicon nitride, Journal of Materials Science, 11[3] (1976) 500-509.

[18] G. Blugan, D. Wittig, and J. Kuebler, Oxidation and corrosion of silicon nitride 
ceramics with different sintering additives at 1200 and $1500{ }^{\circ} \mathrm{C}$ in air, water vapour, $\mathrm{SO}_{2}$ and $\mathrm{HCl}$ environments - A comparative study, Corrosion Science, 51[3] (2009) 547-555. [19] H. Xinmei, C. Kuo-Chih, Investigation of isothermal oxidation of AlN ceramics using different kinetic model, Corrosion Science, 51[3] (2009) 556-561. 


\section{Figure captions}

Fig. 1. Mass gains as a function of oxidation time for all the specimens (Z1, Z2, and Z3) at $1000{ }^{\circ} \mathrm{C}, 1200{ }^{\circ} \mathrm{C}$, and $1400^{\circ} \mathrm{C}$.

Fig. 2. Log mass gain vs. log time for the oxidation at different temperatures (ㄴ. 1000 $\left.{ }^{\circ} \mathrm{C} ; \bigcirc: 1200{ }^{\circ} \mathrm{C} ; \triangle: 1400{ }^{\circ} \mathrm{C}\right)$.

Fig. 3. Mass gains as a function of oxidation time of CS-SPSed $\beta$-SiAlONs, comparing with hot-pressed $\mathrm{Si}_{3} \mathrm{~N}_{4}$ at $1200{ }^{\circ} \mathrm{C}$. [SN-A: $\mathrm{Si}_{3} \mathrm{~N}_{4}$ with $\mathrm{Al}_{2} \mathrm{O}_{3}$ as sintering aid; SN282: $\mathrm{Si}_{3} \mathrm{~N}_{4}$ with $\mathrm{Lu}_{2} \mathrm{O}_{3}$ as sintering aid]

Fig. 4. Photos showing the specimens after $100 \mathrm{~h}$ oxidation, the colour of which changes with temperature.

Fig. 5. XRD patterns of the surfaces of $\beta$-SiAlON discs before and after oxidation for 100 h; (a) Z1, (b) Z2, and (c) Z3. [Mullite: JCPDS 15-0776; $\mathrm{SiO}_{2}$ : JCPDS 29-0085; $\beta-\mathrm{Si}_{5} \mathrm{AlON}_{7}$ : JCPDS 48-1615; $\beta-\mathrm{Si}_{4} \mathrm{Al}_{2} \mathrm{O}_{2} \mathrm{~N}_{6}$ : JCPDS 48-1616; $\beta-\mathrm{Si}_{3} \mathrm{Al}_{3} \mathrm{O}_{3} \mathrm{~N}_{5}:$ JCPDS 36-1333.].

Fig. 6. SEM images of the surfaces of specimens oxidized at $1000{ }^{\circ} \mathrm{C}$ for $100 \mathrm{~h}$; (a) Z1, (b) Z2, and (c) Z3.

Fig. 7. SEM images of the surfaces of specimens oxidized at $1200{ }^{\circ} \mathrm{C}$ for $100 \mathrm{~h}$; (a) Z1, (b) Z2, and (c) Z3.

Fig. 8. SEM images of the surfaces of specimens oxidized at $1400{ }^{\circ} \mathrm{C}$ for $100 \mathrm{~h}$; (a) Z1, (b) Z2, and (c) Z3. 
Fig. 9. SEM images of the discs after oxidation for $100 \mathrm{~h}$; (a) $\mathrm{Z} 1$ at $1400{ }^{\circ} \mathrm{C}$, (b) $\mathrm{Z} 2$ at $1400{ }^{\circ} \mathrm{C}$, (c) $\mathrm{Z3}$ at $1400{ }^{\circ} \mathrm{C}$, and (d) $\mathrm{Z} 1$ at $1200{ }^{\circ} \mathrm{C}$. [(a)-2: magnification of the rectangle area in (a)-1; (b)-2: magnification of the rectangle area in (b)-1].

Fig. 10. SEM images of the cross-sections of the discs oxidized at $1400{ }^{\circ} \mathrm{C}$ for $100 \mathrm{~h}$, (a) Z1, (b) Z2, and (c) Z3.

Fig. 11. Schematic illustration of the oxidation mechanism of $\beta$-SiAlONs.

\section{Table captions}

Table 1 Starting compositions for combustion synthesis of different samples.

Table 2 Densities of the CS-SPSed $\beta$-SiAlONs.

Table 3 EDS analysis results of the marked points shown in Figs. 7 and 8. 


\section{Table 1}

\begin{tabular}{ccccc}
\hline Sample name & $\mathrm{Si}$ & $\mathrm{Al}$ & $\mathrm{SiO}_{2}$ & $\beta-\operatorname{SiAlON}(z=1)$ \\
$($ mass\%) & $($ mass\%) & $($ mass\%) $)$ & 45.0 \\
$\mathrm{Z} 1(\mathrm{z}=1)$ & 37.9 & 8.1 & 9.0 & 40.0 \\
$\mathrm{Z} 2(\mathrm{z}=2)$ & 25.4 & 16.4 & 18.2 & 35.0 \\
\hline
\end{tabular}


Table 2

\begin{tabular}{cccc}
\hline Sample name & Average bulk & Theoretical density & Relative density \\
& density $\left(\mathrm{g} / \mathrm{cm}^{3}\right)$ & $\left(\mathrm{g} / \mathrm{cm}^{3}\right) *$ & 98.8 \\
$\mathrm{Z} 1(\mathrm{z}=1)$ & 3.129 & 3.168 & 99.5 \\
$\mathrm{Z2}(\mathrm{z}=2)$ & 3.107 & 3.122 & 99.5 \\
\hline
\end{tabular}

* Data from reference [16] 
Table 3

\begin{tabular}{lccccc}
\hline \multicolumn{2}{c}{ Elements } & $\mathrm{N}$ & $\mathrm{O}$ & $\mathrm{Al}$ & $\mathrm{Si}$ \\
\hline & Point (1) & 0.00 & 52.16 & 9.40 & 38.44 \\
Mass\% & Point (2) & 0.00 & 49.28 & 36.26 & 14.45 \\
& Point (3) & 0.00 & 50.07 & 27.44 & 22.49 \\
& Point (4) & 0.00 & 48.96 & 36.78 & 14.26 \\
\hline
\end{tabular}




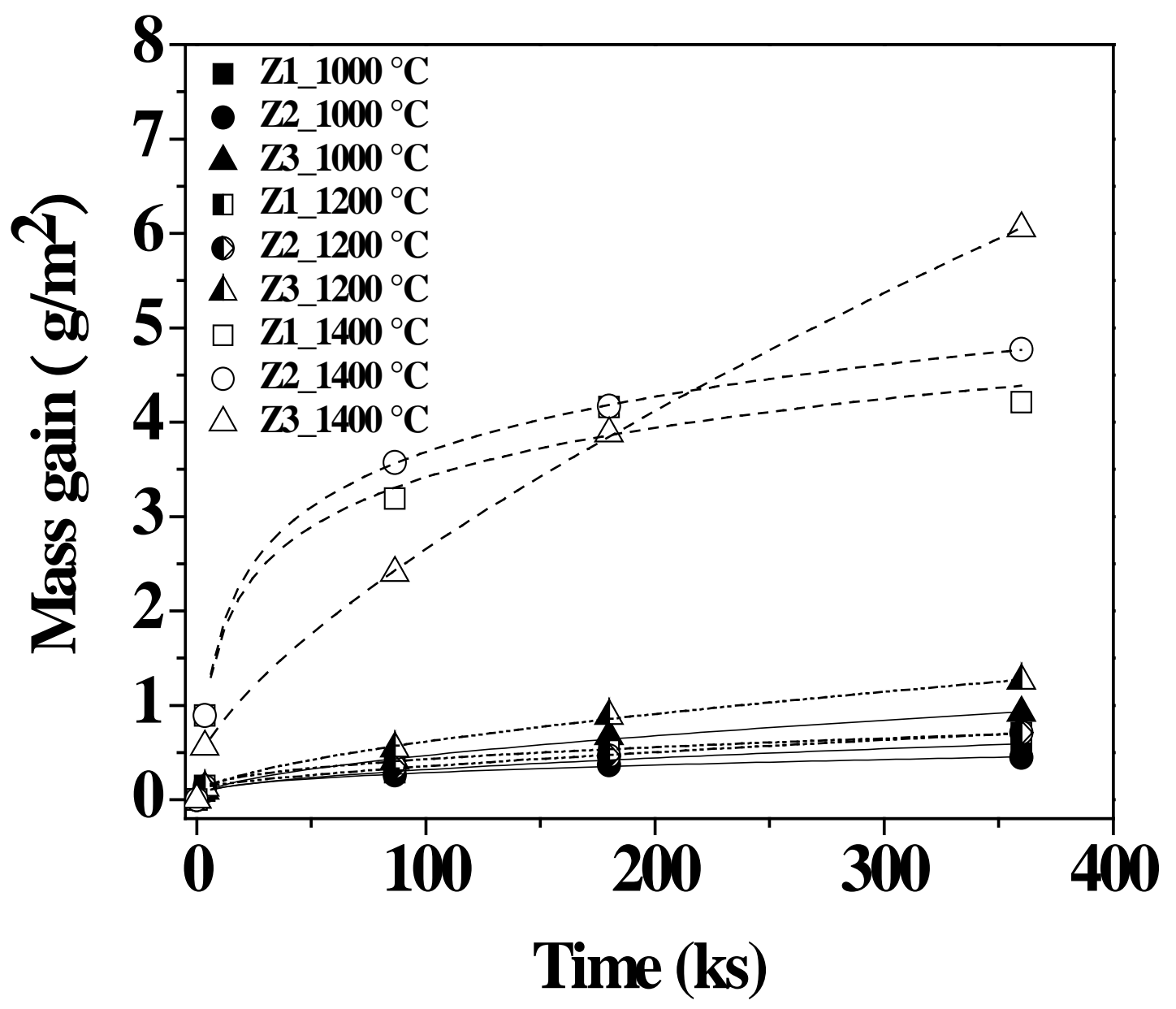

Fig. 1 


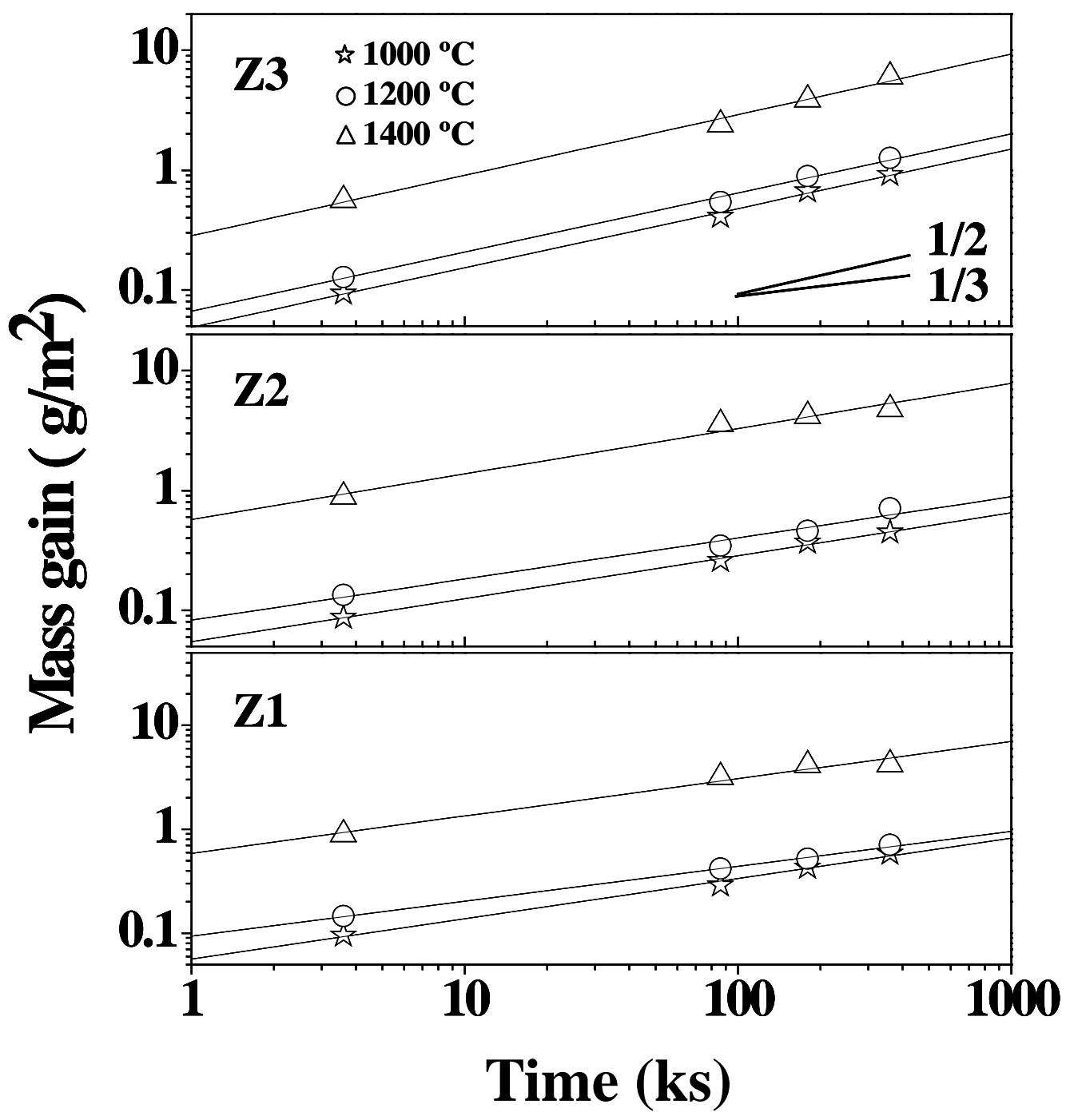

Fig. 2 


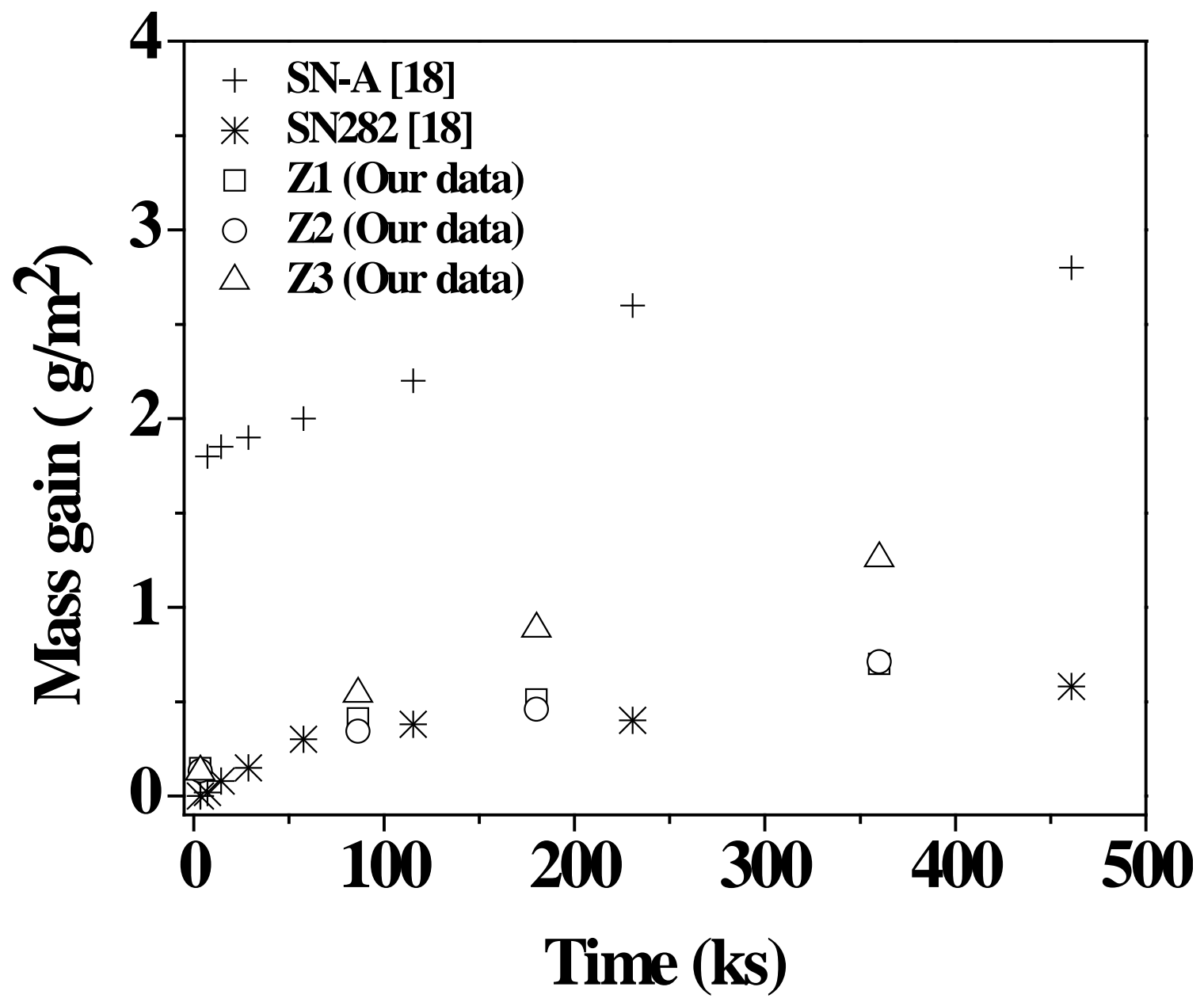

Fig. 3 


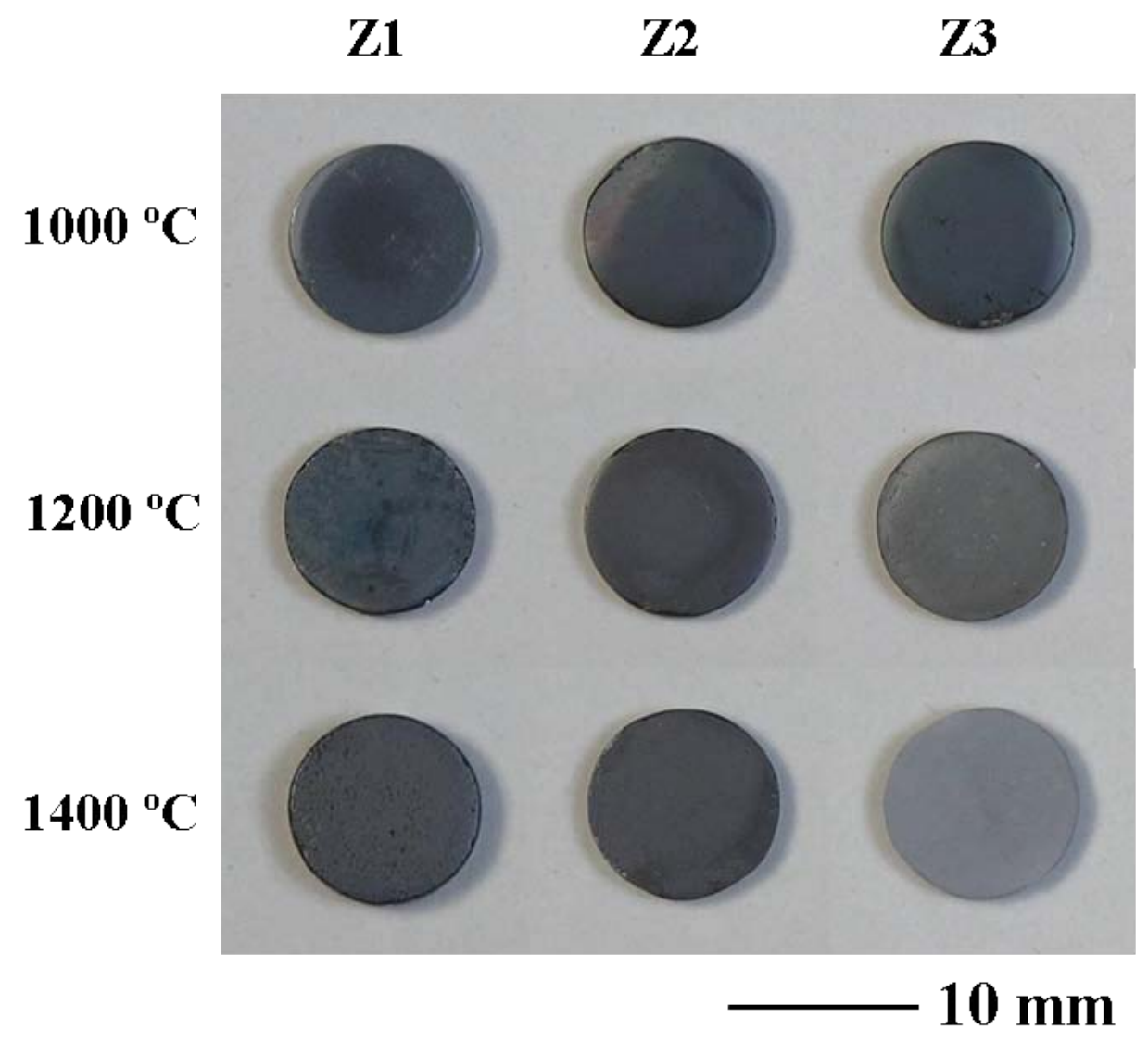

Fig. 4 
(a)

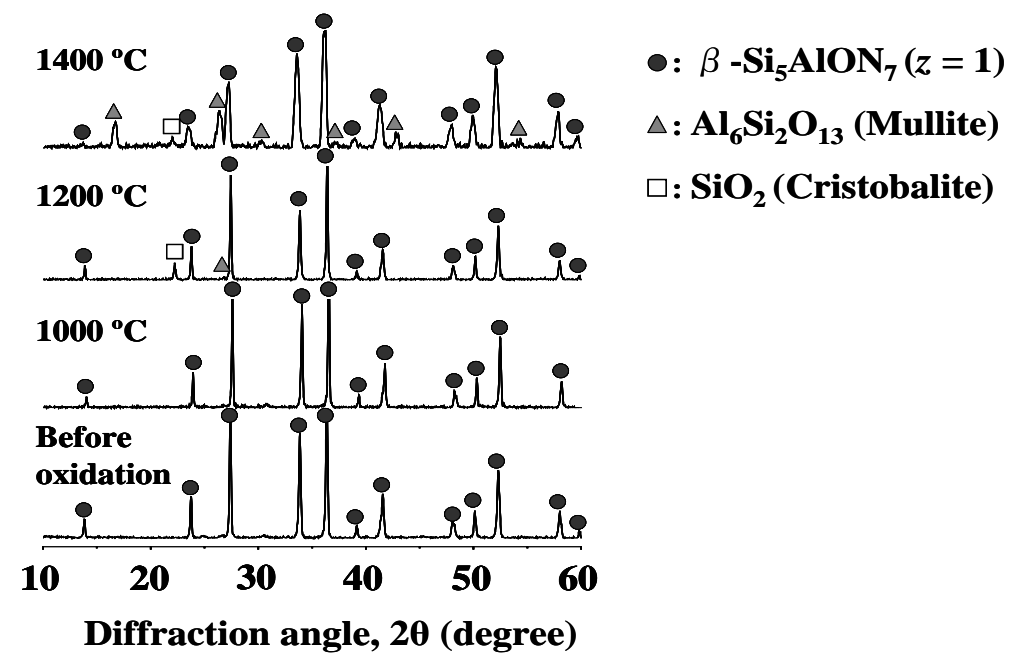

(b)
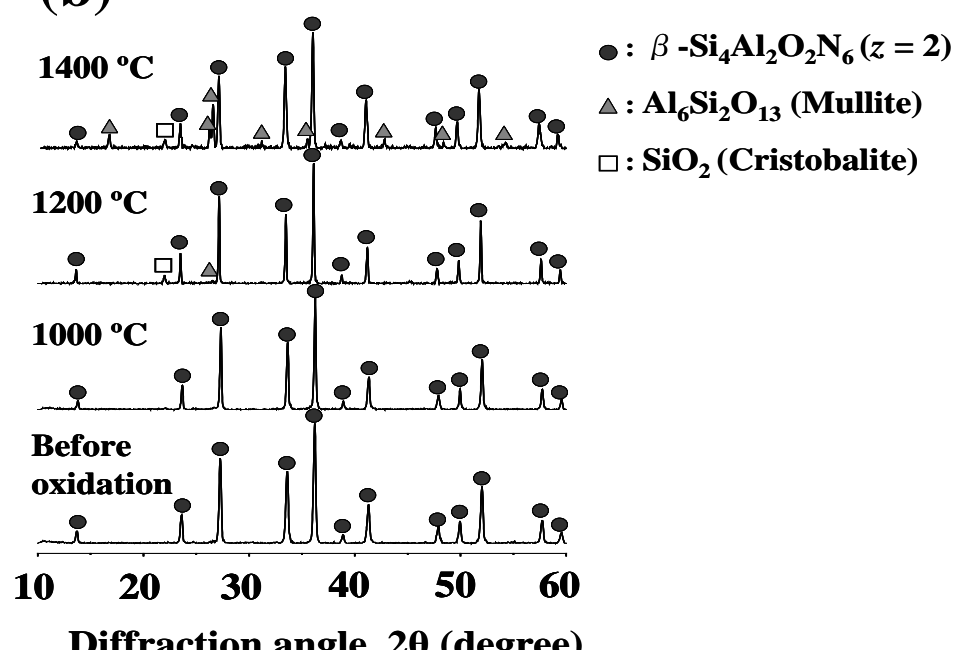

Diffraction angle, $2 \theta$ (degree)

(c)

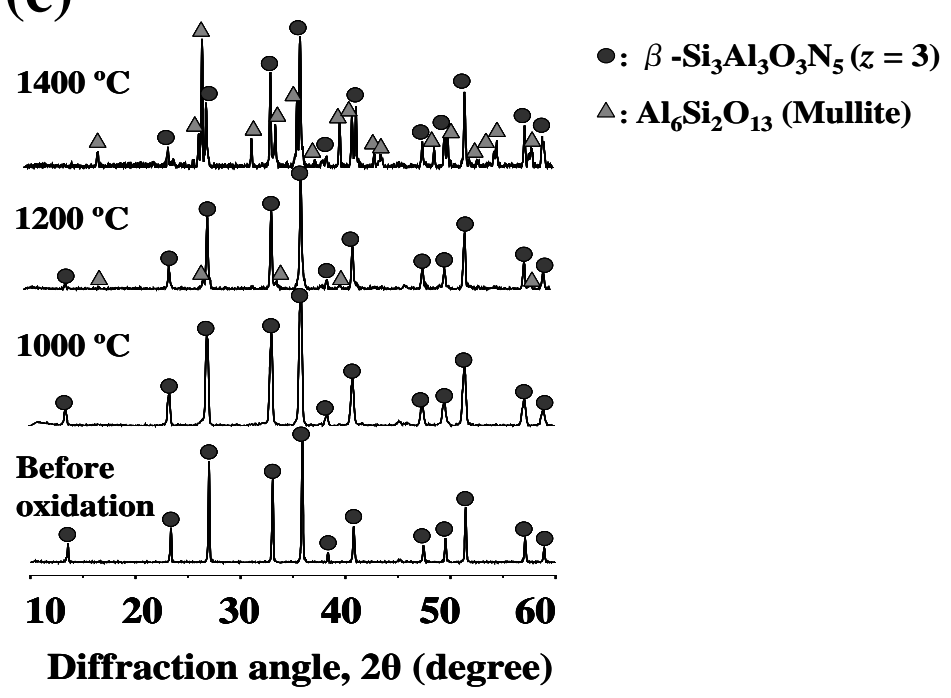

Fig. 5 


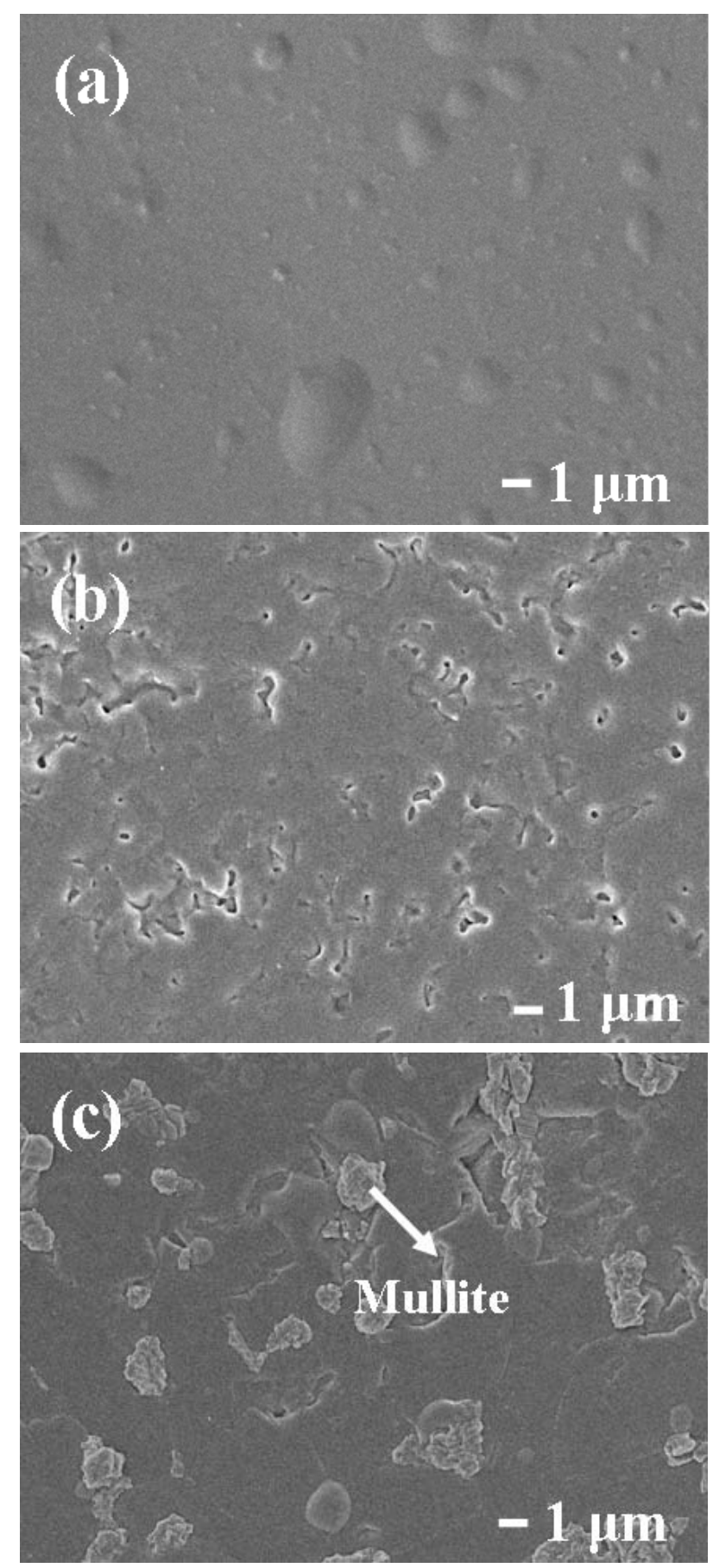

Fig. 6 

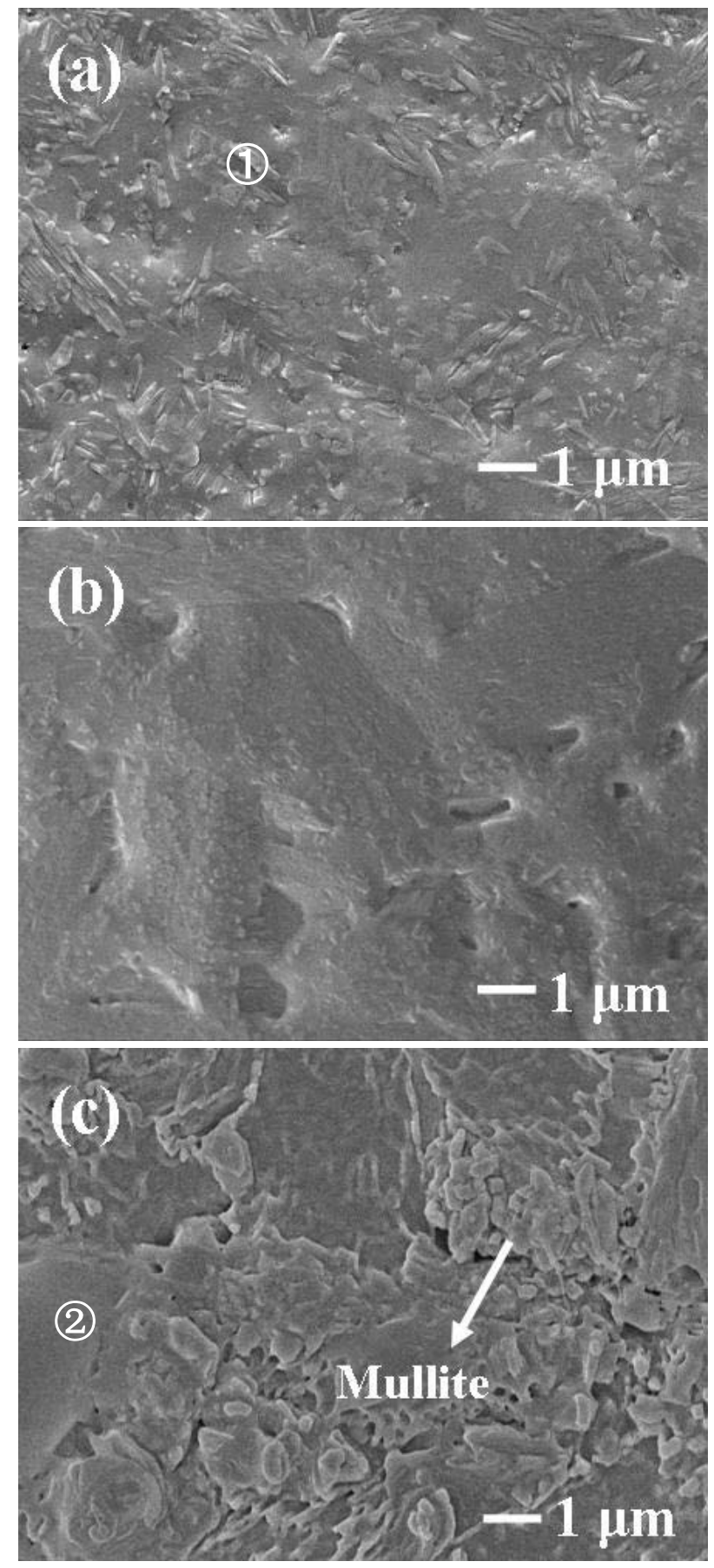

Fig. 7 

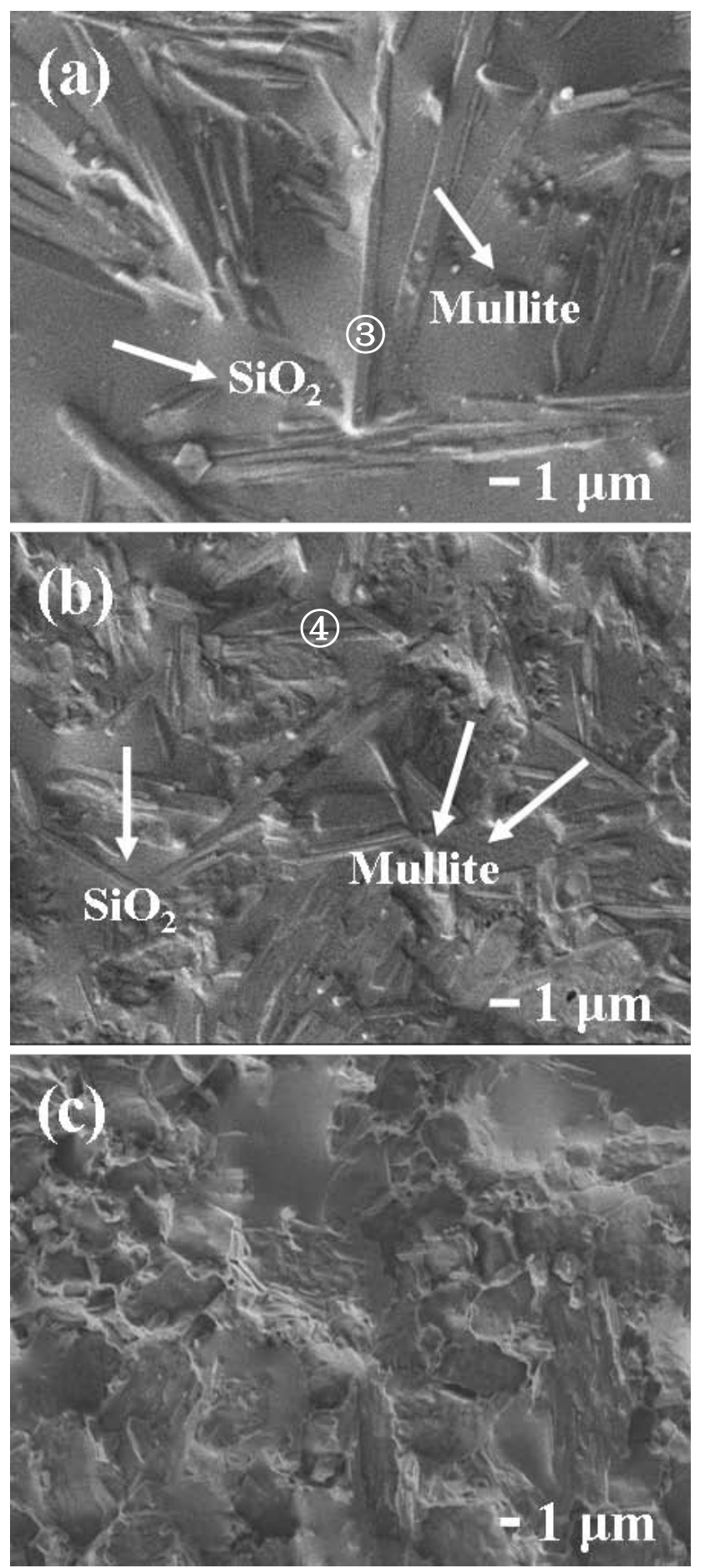

Fig. 8 

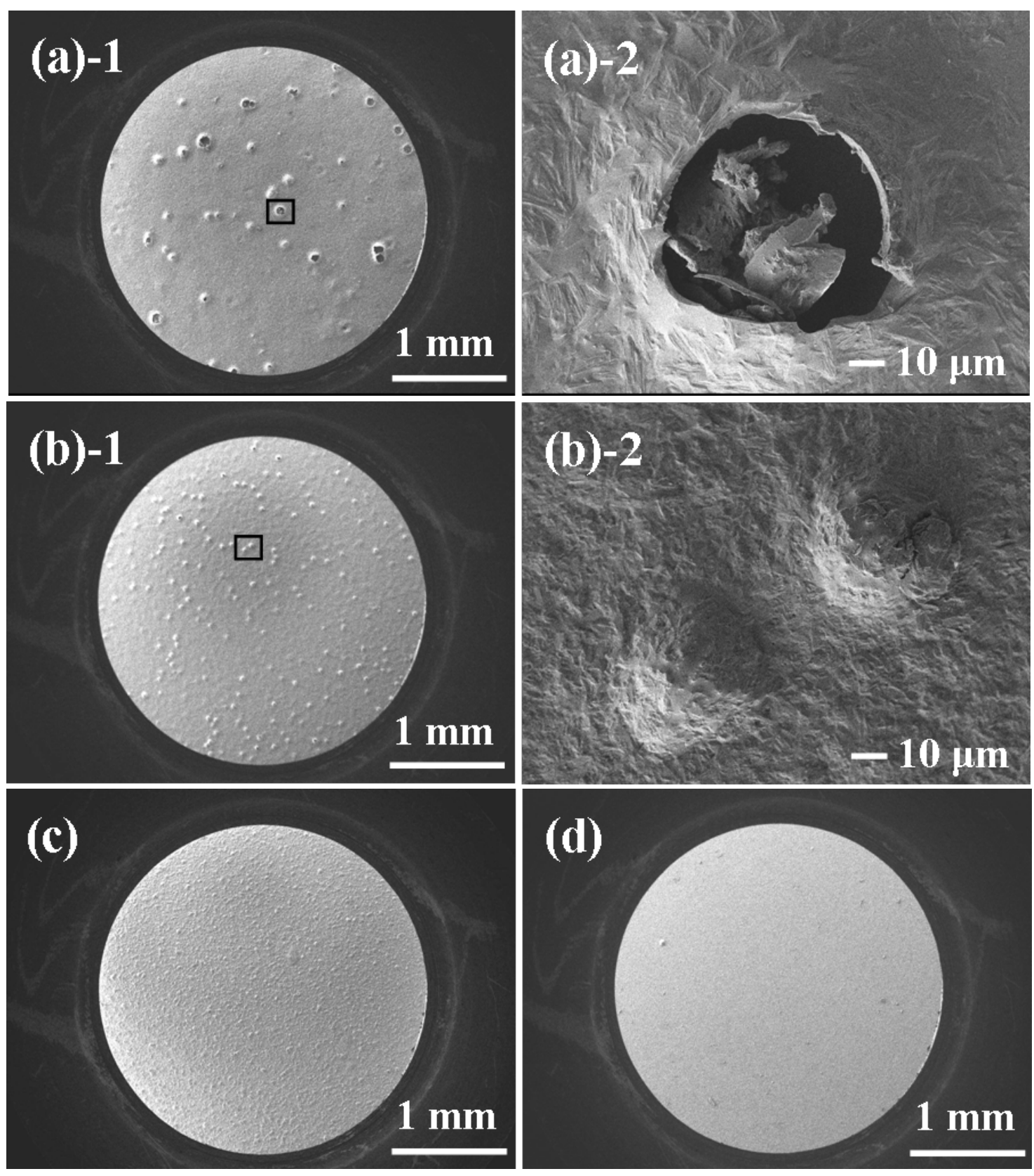

Fig. 9 

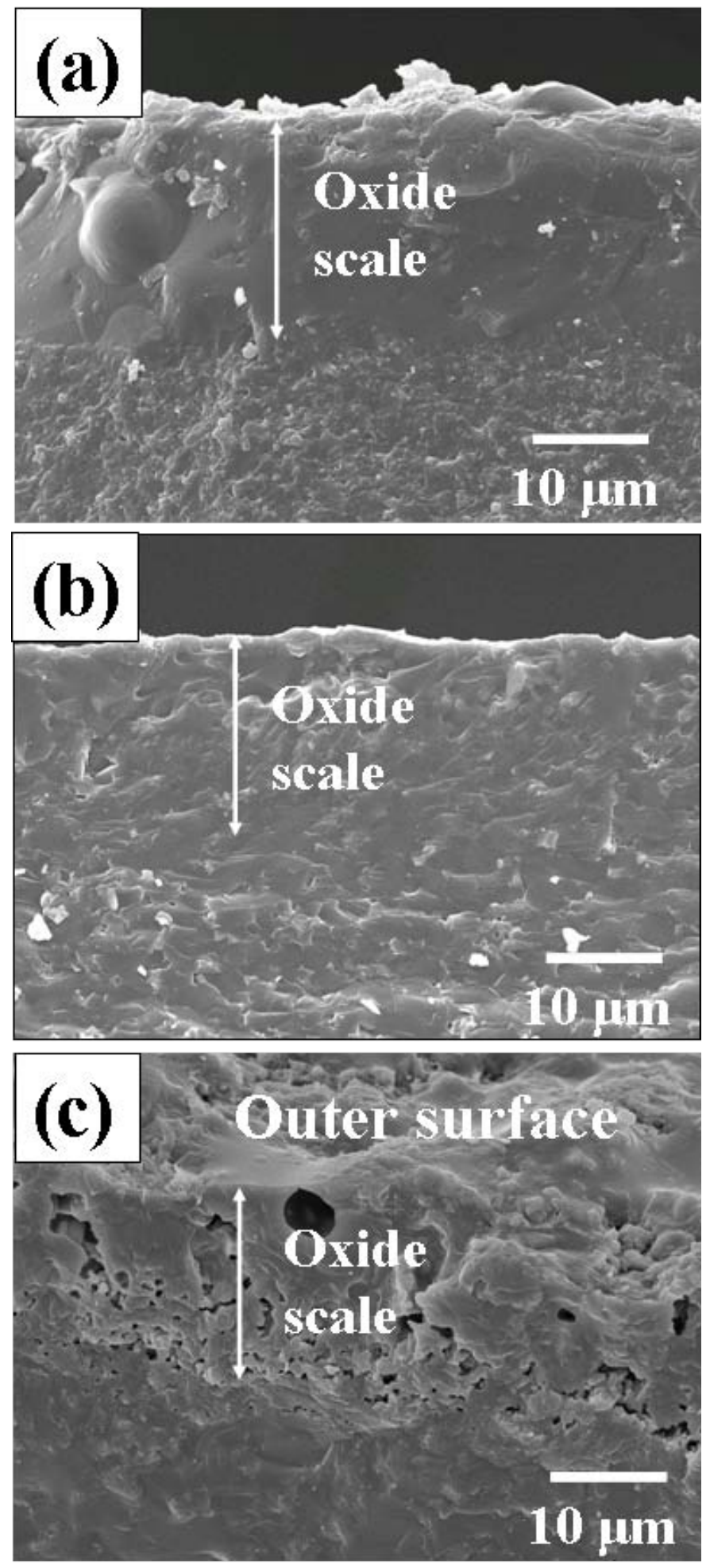

Fig. 10 


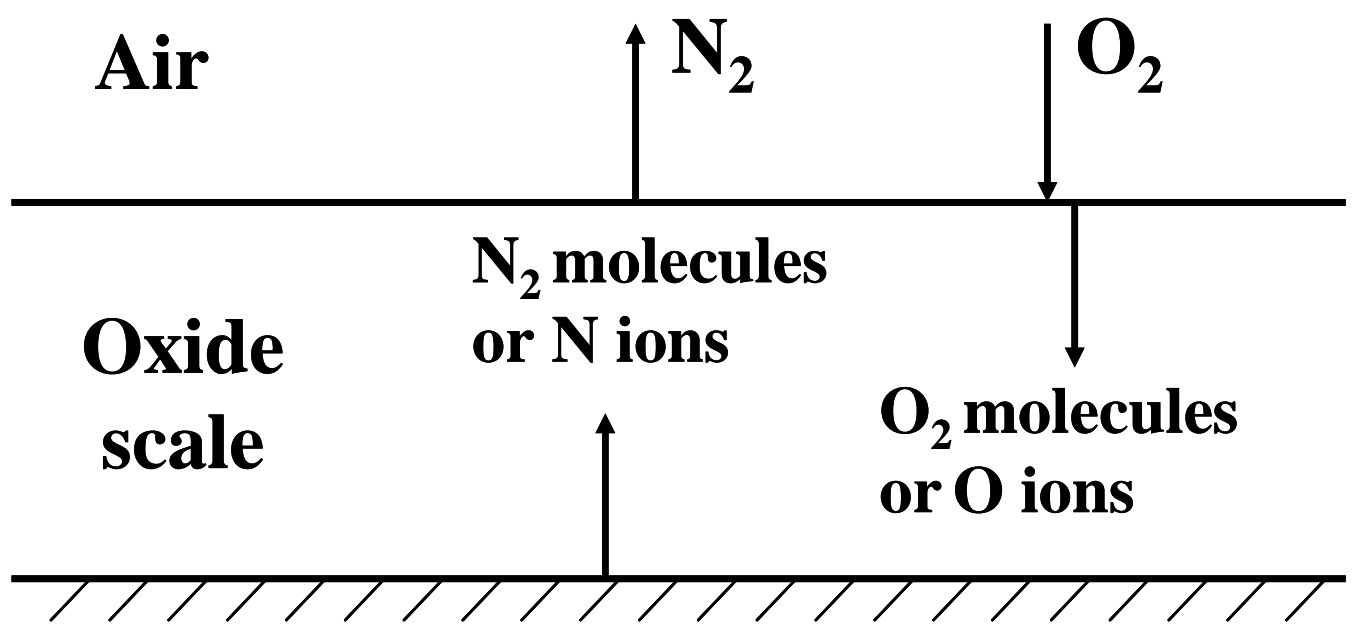

SiAlON

Fig. 11 